\title{
Nutrition at the End of Life: Basic Care or Treatment?
}

\section{Garcia FR $^{1 *}$, Martínez $\mathrm{RG}^{2}$ and De Estefani $\mathrm{RJ}^{3}$}

${ }^{1}$ Municipal Health and Consumer Unit, Guadix Town Hall, Spain

${ }^{2}$ School of Pharmacy, Department of Nutrition and Bromatology, University of Granada, Spain ${ }^{3}$ Department of Philosophy of Law, National Distance Education University Madrid, Spain

*Corresponding author: Francisco Rivas Garcia, Municipal Health and Consumer Unit, Guadix Town Hall, Granada, Spain, Email: saludyconsumo@guadix.es

\section{Review Article \\ Volume 4 Issue 4}

Received Date: September 15, 2021

Published Date: October 06, 2021

DOI: $10.23880 /$ abca-16000203

\section{Abstract}

The end of life involves consideration of a series of interventions, including nutrition and hydration, which can be considered as either basic care or treatment and which influence the approach to clinical care that can be offered. Although scientific literature is not clear as to this potential duality, it is necessary to take into account all concerns, advantages and disadvantages so that health care professionals can build into their clinical practice a professional criterion that allows consideration of access or limitation to nutrition and hydration based on physiological criteria.

Keywords: Nutrition and Hydration; End of Life; Basic Care; Bioethics

\section{The Role of Nutrition at the End of Life}

There are numerous circumstances that can lead into a state of agony in which no therapeutic treatment is available along with a "state of organic exhaustion that people undergo before dying that involves a gradual shutting down of vital functions" [1] preceding death. Therefore, the last days of a patient's life require special care since new needs and causes of suffering may arise [2].

Vulnerability is a human condition defined by the limit of experience of medical care [3], which in turn is related to genesis of the medical care field where actions would be taken not only to cure a disease but also, when doing so is not possible, to access the resources to establish appropriate palliative care to ensure continuity of the essential functions of the body, as well as optimal psychological and spiritual well-being. This is the only way to avoid a utilitarian anthropological perspective that solely considers life in terms of functional quality [4].

In this regard, assistance is ensured by means of a series of general principles, such as pharmacological and non-pharmacological measures, to control symptoms and provide maximum comfort. These also include nutrition and hydration.

Nutrition at the end of life involves acting on the disruptions in the metabolism of carbohydrates (high catabolism, hyperglycaemia, hyperlactatemia) [5], proteins (catabolism of biological structures, hypoalbuminemia, negative nitrogen balance) and lipids (hyperinsulinism) of an organism that is in a critical state.

This assistance seeks to modify the body's response to insult and prevent the state of malnutrition caused by hypermetabolism and associated comorbidities. Quite often, there may be significant dysfunction in patients' swallowing mechanisms, so ensuring that nutrition requirements are met is one of the most complex aspects to consider and, hence, the need arises to resort to artificial nutrition techniques such as parenteral and enteral nutrition.

It should be noted that nutrition at the end of life is a source of multiple dilemmas on the possibility of administration or withdrawal thereof and this implies evaluation of its benefits and harms. 


\section{Nutrition and Hydration: Basic Care or} Treatment?

At the end of life, nutrition and hydration, which can be administered either orally or parenterally according to the patient's specific requirements, is integrated into the various palliative care interventions to be applied to these patients in order to improve their quality of life in the last days before death.

Existing scientific literature and doctrines currently identify two positions with regard to nutrition and hydration: one considers nutrition and hydration as basic care having an inalienable nature and which cannot be suspended, and the other one considers that nutrition and hydration are medical treatment that would have a waivable nature based on the patient's autonomy.

Therefore, considering nutrition as basic care would imply assuming its inalienable nature since the contribution of nutrients and fluids enables to maintain homeostasis, but insofar as administration thereof involves a benefit and does not harm physical and mental health. However, medical treatments are intended to fight the causes of the pathological process and must be applied to the extent that they result in a benefit for the patient, adequately weighing the risks and inconveniences that they may cause. It is precisely in this field where the issue of futility arises, that is, a completely ineffective treatment.

Everyone, just for being a person and regardless of his/ her health status or condition, is entitled to receive basic care to avoid undermining of his/her dignity. However, medical treatments can lose their mandatory nature when they exceptionally need to be applied through different techniques, becoming extraordinary or disproportionate care. This situation has been called therapeutic excess or therapeutic cruelty.

Studies by authors such as Mitchell J, et al. [6]; Rio MI, et al. [7]; Cotogni P, et al. [8]; Boulanger A, et al. [9]; Doig GS, et al. [10]; Morais SR, et al. [11]; Dev R, et al. [12] and Marcolini EG, et al. [13] have shown that nutrition at the end of life can have psychological benefits, as well as a positive impact on the symptoms associated with the disease such as management of the effects of cancer treatments, weight loss and nausea, maintaining muscle mass, reducing oxidative stress, improving inflammatory processes, minimizing the catabolic state, fighting malnutrition and enhancing the immune system, among others.

Other authors such as Valero MA, et al. [14]; Tanier C, et al. [15]; Boulanger A, et al. [16] and Katzberg HD, et al. [17] attribute a symbolic value to nutrition, with no significant differences from other life support techniques, and that like any other technique, it can sometimes be harmful and should be withdrawn to prevent therapeutic cruelty.

Therefore, given this controversy about the usefulness of nutrition and hydration at the end of life, each case should be studied individually taking into account the patient's circumstances and the benefits and risks of the interventions. However, reduced nutrition can give rise to a conflict among patient and family since it can be associated with a feeling of abandonment due to the fact that the patient is not being fed [15-20].

With regard to hydration at the end of life, a series of reasons should be presented that argue in favor of its use since it promotes the well-being of patients, improves the symptoms of the disease, quenches thirst, does not prolong agony and prevents abandonment of patients [21,22]. On the other hand, there are arguments against hydration since it is considered an invasive measure that causes suffering, prolongs agony, and generates an accumulation of fluids such as bronchial secretions, pleural effusion, oedema and ascites. Therefore, although arguments are varied, it is true that oftentimes both patient and family perceive hydration as care and assistance, so it should be maintained until the end [23].

Published studies do not show a significant benefit for sick people from use of palliative care, and any benefits that actually exist appear to be insufficient. Quality studies report on a series of recommendations of practical utility, which can lead to inconsistencies in the results and a limitation in the recommendations for or against the use of hydration and nutrition at the end of life. In fact, individual studies show an improvement in certain symptoms, but benefits are shortlived and must be weighed against patient preferences and the risks that malnutrition can pose [24].

All of the above implies a wide range of clinical situations in connection with certain patients and/or situations, which must be preceded by an ethical reflection covering objective clinical aspects. It is necessary to analyses each patient's characteristics and his/her social, family and economic circumstances before limiting access to nutrition. Given that there is neither medical or social consensus nor any universal ethical guidelines to consider nutrition and hydration either as basic care or as treatment, it becomes clear why there are no clear legal regulations on the role of nutrition and hydration at the end of life.

With regard to hydration, numerous studies have raised controversy as to the benefits and drawbacks. Arguments in favor of parenteral hydration include emotional well- being, alleviation of symptoms of dehydration (hallucinations, 
myoclonic, fatigue and sedation), not prolonging agony, prevention of delirium and increased renal perfusion [2426]. However, certain studies have shown certain issues related to parenteral hydration such as worsening of both overall and lung oedema, increased bronchial secretions, pain, erythema, pleural effusion, ascites and dyspnoea, hypotension, nausea, and constipation [25,27]. Moreover, importance of hydration in the control of neurological symptoms has also been observed in patients who are not in the terminal phase [28].

Although artificial nutrition is not recommended in the terminal phase, hydration is an element of contention and scientific literature sheds no light to clarify conflicting studies. In this regard, the following has been described:

- The effects of hydration on comfort, symptoms, and length of survival appear to be limited [29].

- Cultural and religious beliefs can condition decisionmaking on the use of hydration at the end of life. Cultural norms have been suggested to significantly influence attitudes and decisions about hydration at the end of life $[30,31]$.

- There are no differences in survival rate on the basis of hydration [32].

- Parenteral hydration is not useful in patients that are near death [32].

- Reduced fluid intake does not compromise kidney function [32].

- Family members and medical personnel lack adequate knowledge to understand and properly assess the extent of hydration [33].

- Some improvement is observed in certain symptoms, but the benefits are short-lived and must be weighed against the patient's preferences and the risks that dehydration can pose [34].

- The sensation of dryness at the end of life is not always related to hydration since this is often caused by problems in the oral mucosa [35].

With respect to parenteral hydration at the end of life, ESPEN points out that there is no evidence of a benefit, but that it should be administered according to the patient's evolution and capacity. Other recommendations include withdrawal in the event of absence of a benefit and respecting the decisions of the patient and his/her advance living will, if any.

Its use is also recommended in cases of vegetative state, intensive care or dementia, provided that no advance directives exist and insofar as application does not generate futility. Accordingly, each situation should be individually assessed considering the benefits vis-à-vis the risks and the proportionality of applying hydration to what is required [36].

Faced with this discrepancy in positions on parenteral hydration, application of the principles of bioethics may be useful. Thus, according to the principle of non- maleficence, if it does not provide any benefits and causes a situation of medical futility, then its withdrawal would be justified. On the other hand, taking into account the principle of justice, its contribution would be necessary to guarantee an equitable distribution of means and resources.

Considering the principle of autonomy, it would be possible for the patient to reject administration of hydration. Notwithstanding, the principle of beneficence whereby as long as parenteral hydration represents a benefit, even if it is only emotional and not physical, cannot be ignored and then hydration should be administered [36].

Therefore, given this controversy on usefulness of hydration, each case should be considered individually taking into account the patient's individual circumstances and the specific benefits and risks. Hydration is commonly considered as ordinary means and, therefore, basic care that everyone should receive regardless of their condition. However, in certain irreversible cases, it is thought that hydration should not be considered mandatory if, after clinical assessment of the patient, the harms outweigh the benefits [37].

Proportionality in the use of the means and resources for parenteral hydration allows evaluating the positive effects of the treatment as well as the negative ones such as lack of comfort or pain. Futility is related to usefulness of the treatments and, consequently, a treatment is considered futile when benefits are observed in less than $5 \%$ of the patients treated. Another important aspect to highlight is the effect of the application of technological resources on patients' quality of life and their degree of autonomy. These criteria, i.e., proportionality, futility and quality of life, interfere in bioethical dilemmas, complicating decisions on the usefulness of end-of-life treatments [38].

From the position of basic care, nutrition and hydration are culturally understood as a symbol of care for life. Anthropologically, nutrition is associated from birth with a vital basic need and is attributed a meaning of respect for life and care for fellow men.

This symbolic value, like any other symbol, is connected directly with people's emotions. This explains why in ethical discussions about decisions to limit or even withdraw life support, and even more importantly in the case of nutrition, 
arguments based on emotional ethics arise vis-à-vis arguments of a more rational nature [39].

Considering palliative care as care that improves the quality of life of patients and their families given issues associated with life-threatening diseases are addressed in order to prevent and alleviate suffering, then nutrition would be part of this type of care as the vast majority of patients face numerous nutritional deficiencies. On the other hand, if it is considered a treatment, when patients make decisions about the means that they want or do not want to be applied, nutrition would be freely available and therefore waivable.

Many health care professionals consider hydration and nutrition as an ordinary measure, while others believe this to be an extraordinary one. And many believe that there is no moral difference between different life-sustaining techniques such as mechanical ventilation or dialysis and nutrition and hydration. There are numerous bioethical dilemmas about the importance of hydration and nutrition at the end of life. And obviously, given that a disease has several phases, it would then be possible to consider that there are phases in which they should be applied and others in which they should not. But the proposition is not to establish a differentiation based on the evolution and state of the pathology and rather to highlight the importance of hydration and nutrition to maintain quality of life of patients at the end of life [40].

Given the possibility that nutrition and hydration can be considered a treatment, what criteria should be taken into account to proceed to withdrawal or lack of administration? There is no precise protocol since each patient should be treated in an individualized manner as prognosis and evolution can be variable and require the making of different decisions.

This does not imply that the decision adopted should be based on various considerations such as:

- The decision will not violate the principles of bioethics. Compliance with bioethical principles constitutes the basis for action. Thus, the principle of autonomy must respect the existence of advance healthcare directives.

- $\quad$ The patient's autonomy must be respected and guided so that he/she can participate in the decision-making process, which would imply excellence in professional practice that would ensure that patients are autonomous to decide on their clinical, emotional and spiritual situation.

- Consider and assess the benefits vis-à-vis the complications. Before withdrawing nutrition, benefits vis-à-vis complications must be objectively determined.

- Nutrition at the end of life does not imply its maintenance until the end. In the event of complications or clinical signs that make it advisable, nutrition should be withdrawn in the last days preceding death. In fact, in a state of agony, hydration can worsen the situation.

- Financial considerations shall not condition access to or withdrawal of nutrition. There is sufficient legislation and bioethical criteria to guarantee that access to nutrition is never prevented by financial considerations.

\section{Criteria to Assess the Role of Nutrition and Hydration}

There is a great void in formal prospective trials on the role of nutrition and hydration at the end of life, so the perspectives of patients, family and caregivers provide the basis for decisions as to whether nutrition and hydration are considered basic care or waivable treatment. Such decisions can be conditioned by various criteria:

\section{Socio-Family Criteria}

When pharmacological treatment is no longer effective, it must be suspended and everything that allows the patient not to suffer from hunger, thirst and pain must be provided instead. Ensuring the psychological and spiritual support that the patient may require should not be overlooked. Family members tend to view artificial nutrition as an effective measure as they consider that it helps to improve the level of comfort, dignity and quality of life [41].

\section{Cultural Criteria}

There are cultural differences regarding the meaning of continued nutrition at the end of life. In Western cultures, eating is paramount to survival, and the lack of nutrition accelerates death. But in the Hindu tradition, decreasing oral consumption signifies mortality, but is not a cause of it. The thinking is that at the end of life, a person voluntarily stops eating to prepare for a dignified death. In contrast, the Taiwanese cultural belief is that a person should not die hungry, as his/her soul will be restless, thus the preference is to provide nutrition and hydration [42].

\section{Religious Criteria}

Various postulates are to be considered and so, according to the Catholic Church, providing nutrition and hydration, even by artificial means, are in principle an ordinary and proportionate means for the preservation of life. Consequently, it is mandatory as long as it shows to accomplish its end, which is hydration and nutrition of the patient. This avoids suffering and death from starvation and dehydration $[43,44]$. On the other hand, the Protestant Church has a liberal, less conservative conception to limiting access to and withdrawal of nutrition and hydration if it is necessary [45]. In Jewish Halacha, life is considered 
as a high-priority value and, consequently, nutrition and hydration are considered as basic care; however, if suffering or complications are caused, withdrawal is accepted if it is known to be the patient's wish [46].

The Islamic religion also considers nutrition and hydration as basic care and limiting access is considered to cause greater damage than any possible complications that may arise from administration thereof [47].

\section{Legal Criteria}

There are many real situations where the Law has had to intervene on issues that affect nutrition and hydration. Thus, there are clinical situations that have had social and media impact and in which various rulings have been entered as tools to elucidate the actions to be followed in the face of discrepancies between family members and the medical team. In the Nancy Cruzan, Terri Schiavo [45], Eluana Englano and Vincent Lambert cases, decisions about medical prolongation of life may have been emotionally charged and culturally driven. However, in the judicial sphere, decisions are based on the wishes and/or intent previously stated by the sick person [48].

\section{Bioethical Criteria}

The professional challenge faced by health care providers is to combine the philosophical bases and health care practice with a basis of solidarity, proportionality, justice and individualization. This gives rise to a series of challenging situations with several possibilities for action and making a choice is oftentimes hard because both alternatives are equally good or bad.

Decision-making can be complicated due to many factors, which include the patient, family members and health care professionals. In such cases, two criteria must be applied. One is that of the substitute judgment in which the decision is based on what the patient would have decided. In this case it is assumed that the person who makes the decision knows the preferences of the patient so as to come close to his/ her intent. The second criterion for assistance is that of the best interests whereby a third party decides for the patient according to what would be best for him/her [36].

\section{Conclusion}

The end of life can give rise to certain doubts regarding the limitation of access to nutrition and hydration, as well as withdrawal thereof. Hence, in order to analyse usefulness, each case should be studied individually taking into account the patient's circumstances vis-a-vis the benefits and risks involved, and not exclusively under the principle of basic care or treatment.

The fact that the primary objective of nutrition and hydration is to maintain the patient's functionality, nutritional status and comfort should not be overlooked, without disregarding the fact that it may be dispensed with when objective scientific data exist and the corresponding assessments show that harm is caused, furthermore when nutrition and hydration fail to contribute to physical, psychological and social well-being.

It is necessary to reduce suffering of the patient and his/ her family and this requires that there be advance planning by health care professionals. A useful step in this regard is the opening of a line of dialogue about the probable evolution of the disease and its complications in the aspects related to nutrition and hydration.

\section{References}

1. Gartner J, Daun M, Wolf J, Bergwelt-Baildon M, Hallek M (2019) Early Palliative Care: Pro, but Please Be Precise!. Oncol Res Treat 42(1-2): 11-18.

2. Marian M (2015) Carbohydrate metabolism. A comparison of stress and non-stress states", In: Cresci G, et al. (Eds.), Nutrition for the Critically Il Patient. A Guide to Practice. Second edition, Boca Raton, Fl, CRC Press, pp: 25-70.

3. Hsu CW (2012) Glycemic control in critically ill patients. World J Crit Care Med 1(1): 31-39.

4. Singer P (2009) Toward protein-energy goal-oriented therapy?. Crit Care 13(5): 188.

5. Honiden S, Inzucchi SE (2015) Metabolic Management during Critical Illness: Glycemic Control in the ICU. Semin Respir Crit Care Med 36(6): 859-869.

6. Mitchell J, Jatoi A (2011) Parenteral nutrition in patients with advanced cancer: merging perspectives from the patient and healthcare provider. Semin Oncol 38(3): 439-442.

7. Del Río MI, Shand B, Bonati P, Palma A, Maldonado A, et al. (2012) Hydration and nutrition at the end of life: a systematic review of emotional impact, perceptions, and decision-making among patients, family, and health care staff. Psychooncology 21(9): 913-921.

8. Cotogni P (2016) Enteral versus parenteral nutrition in cancer patients: evidences and controversies. Ann Palliat Med 5(1): 42-49.

9. Boulanger A, Chabal T, Fichaux M, Destandau M, La Piana 
JM, et al. (2017) Opinions about the new law on endof-life issues in a sample of French patients receiving palliative care. BMC Palliat Care 16(1): 7.

10. Doig GS, Heighes PT, Simpson F, Sweetman EA, Davies AR (2009) Early enteral nutrition, provided within $24 \mathrm{~h}$ of injury or intensive care unit admission, significantly reduces mortality in critically ill patients: a metaanalysis of randomised controlled trials. Intensive Care Med 35(12): 2018-2027.

11. Morais SR (2016) Nutrition, quality of life and palliative care: integrative review. Rev Dor Sao Paulo 17(2): 136140.

12. Dev R (2012) Is there a role for parenteral nutrition or hydration at the end of life?. Curr Opin Support Palliat Care 6(3): 365-370.

13. Marcolini EG, Putnam AT, Aydin A (2018) History and Perspectives on Nutrition and Hydration at the End of Life. Yale J Biol Med 91(2): 173-176.

14. Valero MA, Nido RA, Rodríguez PG, González RS, Moreno Villares JM (2016) Is hydration and artificial nutrition considered as palliative care?. SciELO 21(6): 680-685.

15. Tannier C, Crozier S, Zuber M (2015) Group for ethical reflection in neurovascular (GREEN) of the French Neurovascular Society. Medical, legislative and ethical aspects of stopping artificial nutrition and hydration in severe stroke [Withdrawal of artificial nutrition and hydration in severe stroke: medical, legal and ethical considerations]. Rev Neurol 171(2): 166-172.

16. Boulanger A, Chabal T, Fichaux M, Destandau M, La Piana $J M$, et al. (2007) Opinions about the new law on endof-life issues in a sample of French patients receiving palliative care. BMC Palliative Care 7.

17. Katzberg HD, Benatar M (2011) Enteral tube feeding for amyotrophic lateral sclerosis/motor neuron disease. Cochrane Database Syst Rev 1: CD004030.

18. Carter AN (2020) To What Extent Does Clinically Assisted Nutrition and Hydration Have a Role in the Care of Dying People? J Palliat Care 35(4): 209-216.

19. Dalal S, Del Fabbro E, Bruera E (2009) Is there a role for hydration at the end of life?. Curr Opin Support Palliat Care 6(3): 365-370.

20. Mercadante S, Ferrera P, Girelli D, Casuccio A (2005) Patients' and relatives' perceptions about intravenous and subcutaneous hydration. J Pain Symptom Manage 30(4): 354-358.
21. Barbera F (2008) A vision of the philosophical anthropology of nursing. Empathy as transcendental care.

22. Good P, Richard R, Syrmis W, Jenkins-Marsh S, Stephens J (2014) Medically assisted hydration for adult palliative care patients. Cochrane Database Syst Review 23(4): CD006273.

23. Palma A, Said JC, Taboada P (2011) Is it necessary to artificially hydrate terminal patients? [Should we hydrate terminally ill patients?]. Rev Med Chil 139(9): 1229-1234.

24. Carter AN (2020) To What Extent Does Clinically Assisted Nutrition and Hydration Have a Role in the Care of Dying People?. J Palliat Care 35(4): 209-216.

25. Van der Riet P, Higgins I, Good P, Sneesby L (2009) A discourse analysis of difficult clinical situations in relation to nutrition and hydration during end of life care. J Clin Nurs 18(14): 2104-2111.

26. Borasio GD, Jox RJ (2016) Choosing wisely at the end of life: the crucial role of medical indication. Swiss Med Wkly 146: w14369.

27. Manual de Bioética SE (2019) Christian Authors Library, pp: 150-200.

28. Raijmakers NJ, Fradsham S, van Zuylen L, Mayland C, Ellershaw JE, et al. (2011) Variation in attitudes towards artificial hydration at the end of life: a systematic literature review. Curr Opin Support Palliat Care 5(3): 265-272.

29. Bruera S, Chisholm G, Dos Santos R, Crovador C, Bruera E, et al. (2014) Variations in vital signs in the last days of life in patients with advanced cancer. J Pain Symptom Manage 48(4): 510-517.

30. Gent MJ, Fradsham S, Whyte GM, Mayland CR (2015) What influences attitudes towards clinically assisted hydration in the care of dying patients? A review of the literature. BMJ Support Palliat Care 5(3): 223-231.

31. Hwa YL, Kull MR (2020) The why and how of maintaining hydration during cancer therapy. Curr Opin Support Palliat Care 14(4): 324-332.

32. Sawin KJ, Montgomery KE, Dupree CY, Haase JE, Phillips CR, et al. (2019) Oncology Nurse Managers' Perceptions of Palliative Care and End-of-Life Communication. J Pediatr Oncol Nurs 36(3): 178-190.

33. Good P, Richard R, Syrmis W, Jenkins-Marsh S, Stephens J (2014) Medically assisted hydration for adult palliative 
care patients. Cochrane Database Syst Rev 23(4): CD006273.

34. Wallace AS, Fiveash JB, Williams CP, Kvale E, Pisu M, et al. (2018) Choosing Wisely at the End of Life: Use of Shorter Courses of Palliative Radiation Therapy for Bone Metastasis. Int J Radiat Oncol Biol Phys 102(2): 320-324.

35. Cardenas D (2021) Ethical issues and dilemmas in artificial nutrition and hydration. Clin Nutr ESPEN, 41: 23-29.

36. Bükki J, Unterpaul T, Nübling G, Jox RJ, Lorenzl S (2014) Decision making at the end of life Cancer patients' and their caregivers' views on artificial nutrition and hydration. Support Care Cancer 22(12): 3287-3299.

37. Ndahimana D, Kim EK (2018) Energy Requirements in Critically Ill Patients. Clin Nutr Res 7(2): 81-90.

38. Frost DW, Cook DJ, Heyland DK, Fowler RA (2011) Patient and healthcare professional factors influencing end-oflife decision-making during critical illness: a systematic review. Crit Care Med 39(5): 1174-1189.

39. Del Río MI, Shand B, Bonati P, Palma A, Maldonado A, Taboada $P$, et al. (2012) Hydration and nutrition at the end of life: a systematic review of emotional impact, perceptions, and decision-making among patients, family, and health care staff. Psychooncology 21(9): 913921.

40. Chakraborty R, El-Jawahri AR, Litzow MR, Syrjala KL, Parnes AD (2017) A systematic review of religious beliefs about major end-of-life issues in the five major world religions. Palliat Support Care 15(5): 609-622.

41. Pauls M, Hutchinson RC (2002) Bioethics for clinicians: 28. Protestant bioethics. CMAJ 166(3): 339-343.

42. Bülow HH, Sprung CL, Reinhart K, Prayag S, Du B, et al. (2008) The world's major religions' points of view on end- of-life decisions in the intensive care unit. Intensive Care Med 34(3): 423-430.

43. Alsolamy S (2017) Islamic views on artificial nutrition and hydration in terminally ill patients. Bioethics 28(2): 96-99.

44. Brody H, Hermer LD, Scott LD, Grumbles LL, Kutac JE, et al. (2011) Artificial nutrition and hydration: the evolution of ethics, evidence, and policy. J Gen Intern Med 26(9): 1053-1058.

45. Annas GJ (2005) "Culture of life" politics at the bedside the case of Terri Schiavo. N Engl J Med 352(16): 17101715 .

46. Spagnolo AG (1999) Will of patients and accuracy of "surrogate decision makers". Medicine and Morals 49: 395-399.

47. Welie J (2001) Livings Wills and Substituted Judgment: A Critical Analysis. Med Health Care Philos 4(2): 169-183.

48. Mahon MM (2010) Clinical decision making in palliative care and end of life care. Nurs Clin North Am 45(3): 345362.

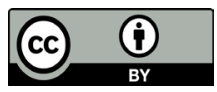

